\title{
Adulterated stingless bee honey identification using VIS-NIR spectroscopy technique
}

\author{
${ }^{1}$ Azmi, M.F.I.,,${ }^{1, *}$ Jamaludin, D., ${ }^{1}$ Abd. Aziz, S., ${ }^{2}$ Yusof, Y.A. and ${ }^{1}$ Mustafah, A.M. \\ ${ }^{1}$ Department of Biological and Agricultural Engineering, Faculty of Engineering, Universiti Putra \\ Malaysia, 43400 Serdang, Selangor, Malaysia. \\ ${ }^{2}$ Department of Process and Food Engineering, Faculty of Engineering, Universiti Putra Malaysia, 43400 \\ Serdang, Selangor, Malaysia
}

\begin{abstract}
Article history:
Received: 4 May 2020

Received in revised form: 17 June 2020

Accepted: 9 January 2021

Available Online: 17 January 2021
\end{abstract}

\section{Keywords:}

Stingless bee honey,

Adulterated honey,

Soluble solid content,

Moisture content,

Near-infrared,

Data processing.

DOI:

https://doi.org/10.26656/fr.2017.5(S1).035

\begin{abstract}
The objective of this study was to study the ability of the VIS-NIR spectroscopy to classify the pure and adulterated stingless bee honey across the wavelength range of 450$969 \mathrm{~nm}$ using an optical spectrometer. The physicochemical properties such as soluble solid content (SSC) and moisture content (refractive index, RI) of pure and adulterated honey has also been investigated using a refractometer. The result showed that pure stingless bee honey has the highest transmittance rate, SSC and RI value compared to adulterated honey. There are significant differences $(P<0.0001)$ in the transmittance rate, SSC and RI of stingless bee honey over five different types of treatments. The results also showed that VIS-NIR data were good in classifying the samples into different treatments with $99.33 \%$ accuracy rate. About thirty-four wavelengths were found to be the most significant to discriminate the different treatments by principal component analysis (PCA) and linear discriminant analysis (LDA) techniques.
\end{abstract}

\section{Introduction}

Stingless Bees (Kelulut) are social bees that exist in almost every continent, subtropical and tropical areas and live around the world (Kek et al., 2014; Vijayakumar and Jeyaraaj, 2014). There are currently more than 600 known species in 56 named genera (Cortopassi-Laurino et al., 2006). It is not until the 1860 s that researchers found that another type of honey can be collected from a different species of bees called the stingless bee (Ya'akob et al., 2019). Honey produced by a stingless bee is known by several names such as Meliponine honey, pot-honey and also, kelulut honey (Amin et al., 2018).

The farming of the stingless bee honey is known as meliponiculture and is continuously growing as farmers recognize the expanding future in this area. The main reasons contributing to this is that stingless bees do not sting their offenders thus making them easier to manage and the price of the stingless bee honey is comparably higher to that of normal honey (Ávila et al., 2018). The price difference is attributed to the lower production of honey by stingless bees when compared to normal bees (Souza et al., 2006). The stingless bee only produces up to $1-5 \mathrm{~kg}$ of honey per year while the honey bees produce an estimate of $20 \mathrm{~kg}$ of honey per year (Biluca et al., 2016; Chuttong et al., 2016).

Stingless bee honey from all over the world had been studied thoroughly in the past and demonstrates a rich and variable composition (Ávila et al., 2018). This was clarified by the fact that the composition of the stingless bee honey differs according to the floral source and origin (Amin et al., 2018). According to the Codex Alimentarius Commission (CODEX STAN 12-1981), no additives such as food ingredients and food additives shall be added into honey and should be sold as such. While the popularity of the stingless bee honey among the consumers continues to grow with time, it has also attracted attention and is targeted by some irresponsible retailers and processers of the honey by adulteration with cheaper sweetener which resulted in the loss of quality of the pure honey (Chen et al., 2011). The introduction of high-fructose corn syrup (HFCS) in the 1970s by the industry has rouse up the adulteration of honey extensively (Mehryar and Esmaiili, 2011) while some honey manufactures adulterate the pure honey with chemicals and sweeteners such as corn syrups (CS), invert syrups (IS) or high fructose inulin syrups (HFIS) (Mehryar and Esmaiili, 2011; Naila et al., 2018). 
A significant number of studies were published over the years to explore methods for detecting honey adulteration. The physicochemical methods have been the traditional way to detect honey adulterants such as sugar content, moisture content, $\mathrm{pH}$ value, HMF content and ash content (White, 1979; Codex Alimentarius, 2001; Naila et al., 2018). This method needs monotonous preparation of the samples, is relatively time -consuming and also requires complex analytical equipment (Zábrodská and Vorlová, 2015).

Much complex and advance method are being developed constantly (Zábrodská and Vorlová, 2015) to ease the process of detecting honey adulterants such as the Gas Chromatography (GC) (Ruiz-Matute et al., 2010), Liquid Chromatography (LC) analysis (Cotte et al., 2004), Near-Infrared (NIR) spectroscopy (Kelly et al., 2006; Zhu et al., 2010), Fourier Transform Infrared (FTIR) spectroscopy (Gallardo-Velázquez et al., 2009), Protein characterization (Won et al., 2008), Liquid Chromatography Coupled to Isotope Ratio Mass Spectrometry (HPLC-IRMS) (Cabanero et al., 2006), Calorimetric methods (Application of DSC) (Cordella et al., 2003), Stable Carbon Isotope Ratio Analysis (SCIRA) (Padovan et al., 2003; Gallardo-Velázquez et al., 2009) and Fourier Transform (FT) Raman spectroscopy (Paradkar and Irudayaraj, 2002).

The Visible-Near-Infrared (VIS-NIR) spectroscopy technique has been used widely to assess food quality as it appears to be a prominent technique for nondestructive analysis of various biological and biomedical materials ( $\mathrm{Li}$ and Yang, 2012). It is a method that can save time and is inexpensive, rapid, and non-destructive. VIS-NIR spectroscopy technique in combination with multivariate statistical techniques (chemometrics) is the most direct, reliable, and rapid method to obtain information on multiple parameters simultaneously and It is used to measure the quantity of the adulterant and was capable to classify correctly the origin of the honey (Gallardo-Velázquez et al., 2009; Li and Yang, 2012). Based on the reasons stated, the VIS-NIR spectroscopy combined with statistical method has been chosen.

In honey adulteration, water and other food sweetener incorporated are known to affect the moisture content and soluble solid content (SSC) of the honey. The relationship between the water content of the honey and the NIR spectroscopy combined with aquaphotomics has been studied by other researchers and previous results showed that NIR spectroscopy is applicable to detect honey adulteration (Bázár et al., 2016). The SSC of honey that is also studied in this research has likewise been found to be a reliable index of adulteration (Terrab et al., 2004).
Spectral data usually require computational intelligence to analyse, especially data reduction method as these analysis methods will optimise the data processing process, these processes include reducing data processing time, reduce the dimensionality of data and enhance data generalisation by lowering overfitting (Khaled et al., 2020). Due to the reasons mentioned, the data reduction methods were specifically considered for this study.

Principal component analysis (PCA) as a dimensional reduction method often unveils unsuspected relationships between variables that lead to new interpretations of the data. PCA is more of a preliminary process before further tasks since it is frequently used before larger studies such as the classification process. The classification method with Linear Discriminant Analysis (LDA) deals with the approach of minimizing the total probability of misclassification usually to find the projection that maximizes the ratio of scatter among the data of different classes to scatter within the data of the same class which depends on group probabilities and multivariate distributions of the predictors (Welch, 1939; Masnan, et al., 2012). The important trait that obtained by LDA in pattern classification is the way they bring the similar and same class data closer and the different data from the different class farther (Kim et al., 2003; Masnan et al., 2012). While Quadratic Discriminant Analysis (QDA) models the likelihood of each class as a Gaussian distribution, then uses the posterior distributions to estimate the class for a given test point (Friedman et al., 2001). Support vector machines (SVM) (Vapnik, 1982; Noble, 2006) maps the data into a higher dimensional input space and one constructs an optimal separating hyperplane in this space. SVM formulation of computer algorithm of pattern recognition (binary) problems brings massive advantages among any other approach (Mavroforakis and Theodoridis, 2006; Noble, 2006).

The objective of this study was to study the ability of the VIS-NIR spectroscopy to classify the pure and adulterated stingless bee honey across the wavelength range of $450-969 \mathrm{~nm}$. This research also investigates the relationship between the VIS-NIR spectroscopy properties, adulteration percentage and physicochemical properties.

\section{Materials and methods}

\subsection{Honey samples}

Stingless bee honey sample was collected from Trigona itama species on January 2020 at Ladang 10, Universiti Putra Malaysia. The samples afterwards were sealed in a low-temperature freezer at $-20^{\circ} \mathrm{C}$ for storage 
until further analysis. Before the spectral measurement, the samples were placed in the (Memmert WNB 14, Germany) water bath at $45^{\circ} \mathrm{C}$ until the soluble substance fully dissolve. All the samples are then treated with five different treatment. The treatments are pure stingless bee honey and adulterated with $60 \%$ concentration of sucrose solution at the different percentages $(5 \%, 10 \%, 20 \%$, and $30 \%$ ). The samples then continued to be placed in the water bath for another $3 \mathrm{hrs}$ to ensure that the solution is mixed well and dissolve any crystals present in the samples (Yanniotis et al., 2006).

\subsection{VIS-NIR spectroscopy}

VIS-NIR spectroscopy was performed at room temperature $\left(25^{\circ} \mathrm{C} \sim 27^{\circ} \mathrm{C}\right)$ Spectral scanning was conducted by an Optical Spectrometer (Ocean Optic HR4000CG-UV-NIR, USA) (Figure 1) in transmission mode with the recorded wavelength range of $450 \mathrm{~nm}$ to $969 \mathrm{~nm}$ with 2058 wavelength values measured in disposable plastic cuvettes. Before samples measurement, the readings were calibrated with light reference (open light source and empty cuvette on the cuvette holder) and dark reference (with the light source off/blocked) to get optimum and accurate results. The reading of the transmittance rate of each sample was conducted three times and averaged on each sample. At the end of the experiment, the transmittance rate values were saved as Microsoft excels files for statistical analysis.

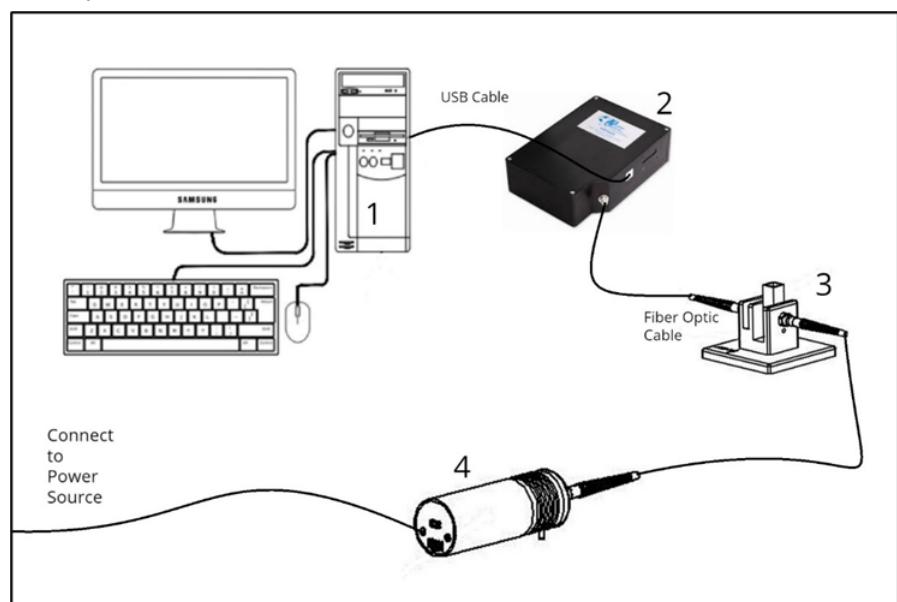

Figure 1. Schematic diagram of VIS-NIR Spectroscopy measurement of Stingless Bee Honey samples, 1: personal computer (PC), 2: Ocean Optic HR4000CG-UV-NIR Spectrometer, 3: Cuvette and Cuvette Holder, 4: Halogen Light.

\subsection{Soluble solid content (SSC)}

SSC of Stingless Bee Honey was determined by $\left(^{\circ}\right.$ Brix) using Abbe Refractometer (KRUSS Digital Abbe refractometer AR2008, Germany) with an accuracy of $\pm 0.1 \%$. Around $0.15 \mathrm{~mL}$ or three drops of every honey samples are needed to carry out the test. The analysis was performed five times and averaged.

\subsection{Moisture content}

Moisture contents were recorded by the refractive index (RI) method. The measurement of the RI was performed using an Abbe refractometer (KRUSS Digital Abbe refractometer AR2008, Germany) the samples were kept at a constant temperature of $20^{\circ} \mathrm{C}$ before the reading was taken. The refractometer was then cleaned and dried before the measure of the next sample. The repeatability of the RI determination was performed three times and averaged (Department of Standards Malaysia, 2017; Codex Alimentarius, 2001)

\subsection{Statistical analysis}

\subsubsection{Principal component analysis (PCA)}

PCA is applied for dimensionality reduction prior to any classification rules and solving singularity issue in LDA. Reduction of data through the elimination of redundant data is important to cater to computational costs especially in handling spectral data with high dimensionality. PCA was perform using MASS package in $\mathrm{R}$ version 3.6.1 software (Lucent Technologies, New Jersey USA). PCA was considered in this study to reduce the dimensionality of the VIS-NIR spectral data into several significant components without changing the underlying value of the overall data (Khaled et al., 2020). Based on Figure 2, an elbow is observed at the third principal component (PC3) hence, only three principal components (PCs) were selected based on their total variance attribute. The selected data were then used as inputs for three classifiers, which were LDA, QDA, and SVM.

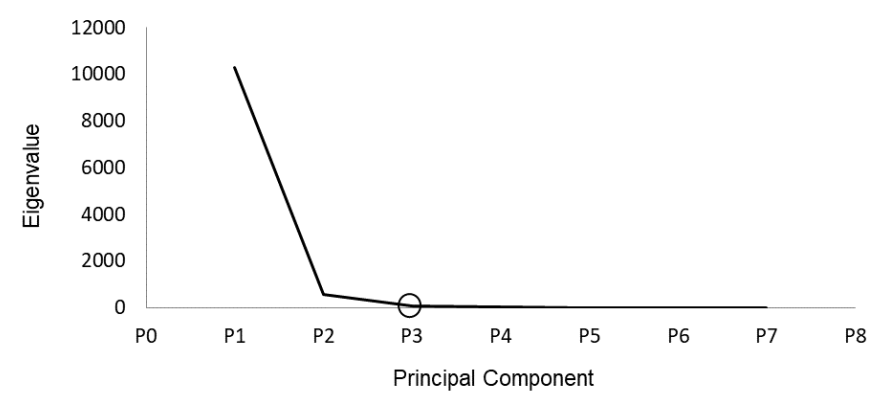

Figure 2. Screen plot to determine the ideal number of principal components to retain

\subsubsection{Linear discriminant analysis (LDA)}

LDA is used to find the linear combination of features which best separate two or more classes of object or event. It required a reduction of the number of variables based on maximizing the ratio between-class vs within-class variance using linear combinations of the original variables to achieve class discrimination (Borràs et al., 2015). The use of LDA required a reduction in the number of variables. The use of PCA as a variable 
reduction tool before LDA requires a careful evaluation of the number of components to be used (Skrobot et al., 2007).

\subsubsection{Quadratic discriminant analysis (QDA)}

QDA classifier was used to maximise the ratio of the determinant of the between level scatter matrix. QDA is closely related to LDA but there is no assumption that the covariance of each of the classes is identical (Balabin et al., 2010).

\subsubsection{Support Vector Machine (SVM)}

The SVM is applied to optimise the marginal perpendicular distance to the hyperplanes in order to distinguish the different levels of data within the training data set. Two parallel hyperplanes are constructed on each side of the hyperplane that separates the data and maximizes the distance between the two parallel hyperplanes. Larger margin or distance between parallel hyperplanes gives better the classifier generalization error (Balabin et al., 2010).

\section{Results and discussion}

3.1 VIS-NIR distribution of stingless bee honey at 450$969 \mathrm{~nm}$ wavelength between treatments.

The plot of the VIS-NIR property (transmittance rate) with five different treatments (pure honey, 5\% adulteration, $10 \%$ adulteration, $20 \%$ adulteration and $30 \%$ adulteration) against wavelength at room temperature $\left(25 \pm 2^{\circ} \mathrm{C}\right)$ is presented in Figure 3. As can be seen, the plot shows changes across the wavelength range of 450-969 $\mathrm{nm}$. Shapes of the spectra of all samples were quite homogeneous where the highest peak of the graph was identified as pure stingless honey samples.

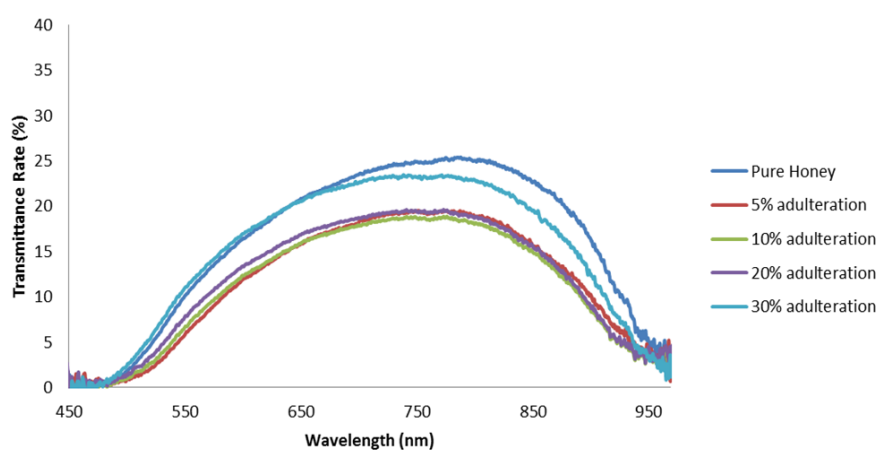

Figure 3. VIS-NIR property (Transmittance Rate) of stingless bee honey against wavelength at five different treatments.
The wavelength of $787.677 \mathrm{~nm}$ was chosen to compare the mean between treatments for SSC and RI because it has the maximum transmittance value compared to the other wavelength and it gives the best signal-to-noise ratio, which improves the precision of measurement. In view of the results obtained, it was found that there were highly significant differences $(\mathrm{P}<$ 0.0001; Table 1) in the transmittance rate of stingless bee honey over 5 different types of treatments. Generally, the mean of transmittance rate (Table 2) of pure stingless bee honey is the highest compared to any adulterated samples.

Table 2. DMRT on the mean transmittance rate of Stingless bee honey.

\begin{tabular}{cc}
\hline Treatment & Mean Transmittance \\
\hline 30\% Adulteration & $23.151 \pm 0.9713^{\mathrm{c}}$ \\
20\% Adulteration & $19.044 \pm 0.5960^{\mathrm{b}}$ \\
$10 \%$ Adulteration & $18.422 \pm 7.8480^{\mathrm{a}}$ \\
$5 \%$ Adulteration & $19.405 \pm 0.9353^{\mathrm{b}}$ \\
Pure Honey & $25.415 \pm 1.7853^{\mathrm{d}}$ \\
\hline
\end{tabular}

Values are expressed as mean \pm standard deviation. Values with different superscript are significantly different $(\mathrm{p}<0.05)$.

The result shows that the addition of sucrose solution to stingless bee honey could increase the transmittance of stingless bee honey samples. This is assumed to occur due to the adulteration process with sucrose solution with higher moisture content and therefore will affect the viscosity of the stingless bee honey, which affects the transmittance. The decrease in the concentration of the stingless bee honey is believed to affect the VIS-NIR properties as expressed by the Lambert-Beer law, which is more commonly known as Beer's law (Equation 1). Beer's law states that the absorbance of a light-absorbing material is proportional to its concentration in solution:

$$
\mathrm{A}=\varepsilon \mathrm{Lc}
$$

Where $\mathrm{A}=$ the absorbance of the materials, $\varepsilon=$ the extinction coefficient of the substance, $\mathrm{L}=$ the sample path length and $\mathrm{c}=$ the molar concentration of the solution

This relation is further related to the VIS-NIR transmittance properties that have been measured. Absorbance is related logarithmically to transmission:

$$
\mathrm{A}=-\log _{10} \mathrm{~T}
$$

Where $\mathrm{A}=$ the absorbance of the materials and $\mathrm{T}=$ the transmittance rate

Table 1. Overall ANOVA for the mean transmittance rate of stingless bee honey.

\begin{tabular}{ccccccc}
\hline Source & Sum of Squares & Degree of Freedom & $\begin{array}{c}\text { Mean } \\
\text { Square }\end{array}$ & F-value & P-Value & $\begin{array}{c}\text { Standard Error of } \\
\text { Mean }\end{array}$ \\
\hline Treatment & 1113 & 4 & 278.25 & 440.331 & $<.0001$ & 0.23216 \\
\hline
\end{tabular}


Table 1. Overall ANOVA for the mean transmittance rate of stingless bee honey.

\begin{tabular}{ccccccc}
\hline Source & Sum of Squares & Degree of Freedom & $\begin{array}{c}\text { Mean } \\
\text { Square }\end{array}$ & F-value & P-Value & $\begin{array}{c}\text { Standard Error of } \\
\text { Mean }\end{array}$ \\
\hline SSC & 121.068 & 4 & 30.267 & 403.374 & $<.0001$ & 0.07684 \\
RI & 0.001 & 4 & 0.00015 & 418.449 & $<.0001$ & 0.00017 \\
\hline
\end{tabular}

The result obtained agreed with previous work carried out by Liu et al. (2020) where it was found that the viscosity may influence the lightness and the transmittance of the tested liquid.

\subsection{Physicochemical properties of stingless bee honey samples between treatments.}

The physicochemical properties results show highly significant differences in the mean of SSC and RI over 5 different treatments $(\mathrm{P}<0.0001)$ (Table 3). Primarily, the mean of SSC and RI were decreased as the adulteration percentage increase, SSC mean value decreased from $69.98 \%$ to $67.47 \%$ while RI mean value decrease from 1.4652 to 1.4594 as adulteration percentage increase from $0 \%$ (unadulterated samples) to $30 \%$ (Table 4). The decreasing in the physicochemical values were expected and may be due to the addition of the sucrose solution to the Stingless bee honey samples which had increased the moisture content of the samples.

Table 4. DMRT on the mean SSC and RI of Stingless bee honey

\begin{tabular}{ccc}
\hline \multirow{2}{*}{ Treatment } & \multicolumn{2}{c}{ Mean Value } \\
\cline { 2 - 3 } & SSC & RI \\
\hline $30 \%$ Adulteration & $67.47 \pm 0.53^{\mathrm{a}}$ & $1.4594 \pm 0.0012^{\mathrm{a}}$ \\
$20 \%$ Adulteration & $68.59 \pm 0.99^{\mathrm{b}}$ & $1.4623 \pm 0.0023^{\mathrm{b}}$ \\
$10 \%$ Adulteration & $69.46 \pm 0.66^{\mathrm{c}}$ & $1.4637 \pm 0.0008^{\mathrm{c}}$ \\
$5 \%$ Adulteration & $69.58 \pm 0.62^{\mathrm{c}}$ & $1.4642 \pm 0.0015^{\mathrm{d}}$ \\
Pure Honey & $69.98 \pm 0.82^{\mathrm{d}}$ & $1.4652 \pm 0.0013^{\mathrm{e}}$ \\
\hline
\end{tabular}

Values are expressed as mean \pm standard deviation. Values with different superscript are significantly different $(p<0.05)$.

\subsection{Dimensional Reduction using Principal Component Analysis (PCA)}

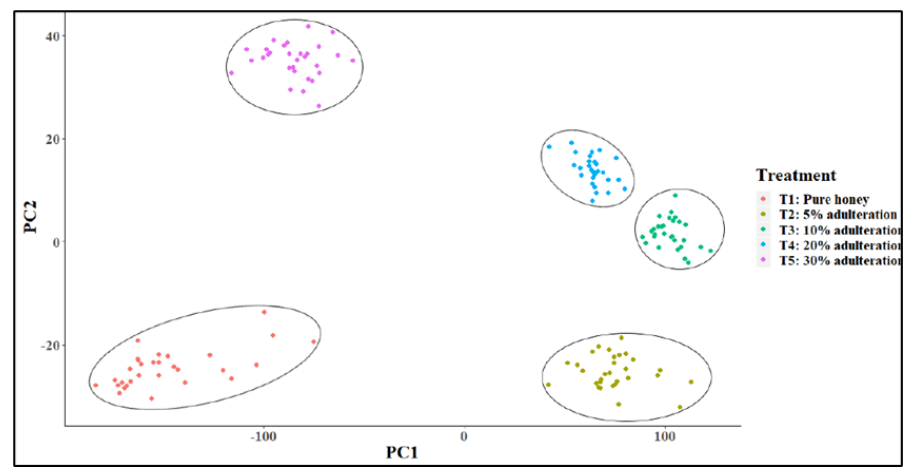

Figure 4. Distribution of samples by treatment based on the first two principal components $\mathrm{PC} 1$ and $\mathrm{PC} 2$.

Figure 4 presents the two-dimensional PC score plot based on the first two components (PC1 and PC2) that were acquired from the raw VIS-NIR spectral data.

It shows that all samples could be graphically clustered well according to each treatment based on the first two principal components. This concludes that the transmittance rate across the wavelength of $450 \mathrm{~nm}$ to $969 \mathrm{~nm}$ can be used to demonstrate a distinct difference between pure and adulterated stingless bee honey.

\subsection{Classification by Linear Discriminant Analysis based on Principal Components (PCA-LDA)}

Table 5 shows the trace proportion of all possible linear discriminants of PCA-LDA method. Based on Table 5, the first linear discriminant (LD1) could explain $85 \%$ variation in all principal components used, while the second (LD2) and the third (LD3) linear discriminants could explain the rest of the $14.81 \%$ and $0.18 \%$ respectively. Next, the linear discriminant model was assessed in terms of the accuracy rate. Based on Table 6, one sample from the third treatment (T3: 10\% adulteration) is misclassified into the first treatment (T1: Pure honey) yielding an accuracy rate of $99.33 \%$. The description of the misclassified sample is presented in Table 7. Table 6 clearly shows that the misclassified sample which is the $16^{\text {th }}$ sample is the closest to the first treatment with a squared distance of 3.888 , followed by the third treatment with a squared distance of 104.446. This justifies the misclassification of the sample.

Table 5. Proportion of trace based on linear discriminant

\begin{tabular}{lccc}
\hline Linear Discriminant & LD1 & LD2 & LD3 \\
\hline Proportion of trace & 0.85 & 0.1481 & 0.0018 \\
\hline
\end{tabular}

Table 6. Confusion matrix which represents the prediction of each sample.

\begin{tabular}{lccccc}
\hline & \multicolumn{5}{c}{ Predicted } \\
\cline { 2 - 6 } & $(1)$ & $(2)$ & $(3)$ & $(4)$ & $(5)$ \\
\hline T1: Pure honey (1) & 30 & 0 & 0 & 0 & 0 \\
T2: 5\% adulteration (2) & 0 & 30 & 0 & 0 & 0 \\
Actual T3: $10 \%$ adulteration (3) & 1 & 0 & 29 & 0 & 0 \\
T4: $20 \%$ adulteration (4) & 0 & 0 & 0 & 30 & 0 \\
T5: 30\% adulteration (5) & 0 & 0 & 0 & 0 & 30 \\
\hline
\end{tabular}

3.5 Classification by Quadratic Discriminant Analysis based on Principal Components (PCA-QDA)

Similar to the result from PCA-LDA, Table 8 also shows that one sample from the third treatment (T3: 10\% adulteration) is misclassified into the first treatment (T1: 
Table 7. Summary of misclassified observations

\begin{tabular}{|c|c|c|c|c|c|}
\hline Observation & True Group & Predicted Group & Group & Squared Distance & Probability \\
\hline \multirow[t]{5}{*}{$16^{* *}$} & T3: $10 \%$ adulteration & T1: Pure honey & T1: Pure honey & 3.888 & 1 \\
\hline & & & $\mathrm{T} 2: 5 \%$ adulteration & 115.004 & 0 \\
\hline & & & T3: $10 \%$ adulteration & 104.446 & 0 \\
\hline & & & T4: $20 \%$ adulteration & 158.424 & 0 \\
\hline & & & T5: $30 \%$ adulteration & 374.405 & 0 \\
\hline
\end{tabular}

Pure honey) yielding an accuracy rate of $99.33 \%$. The description of the misclassified sample is presented in Table 9. Table 9 shows that the misclassified sample which is the $16^{\text {th }}$ sample is the closest to the first treatment with a squared distance of 15.04 , followed by the third treatment with a squared distance of 41.07 .

Table 8. The confusion matrix of PCA-QDA

\begin{tabular}{ccccccc}
\hline & \multicolumn{5}{c}{ Predicted } \\
\cline { 2 - 6 } & $(1)$ & $(2)$ & $(3)$ & $(4)$ & $(5)$ \\
\hline T1: Pure honey (1) & 30 & 0 & 0 & 0 & 0 \\
T2: 5\% adulteration (2) & 0 & 30 & 0 & 0 & 0 \\
Actual & T3: $10 \%$ adulteration (3) & 1 & 0 & 29 & 0 & 0 \\
T4: 20\% adulteration (4) & 0 & 0 & 0 & 30 & 0 \\
T5: 30\% adulteration (5) & 0 & 0 & 0 & 0 & 30 \\
\hline
\end{tabular}

3.6 Support Vector Machine (SVM) based on principal components (PCA-SVM)

Similar to the result from PCA-LDA and PCA-QDA, Table 10 shows that one sample from the third treatment (T3: $10 \%$ adulteration) is misclassified into the first treatment (T1: Pure honey) yielding an accuracy rate of $99.33 \%$.

Generally, all three different methods namely PCALDA, PCA-QDA and PCA-SVM are equally good in classifying the samples into different treatments based on the Visible-near-infrared (VIS-NIR) data as all classification method has the same accuracy rate.

\subsection{Significant wavelength to discriminate the different treatments}

The significant wavelength was determined by conducting the PCA method and the top 100 wavelengths were selected with the highest loadings for the first principal component. The LDA was performed on the same wavelength to identify the first two linear discriminants. Lastly, the wavelength that was in the top 50 of both linear discriminants were selected and as
Table 10. The confusion matrix of PCA-SVM

\begin{tabular}{ccccccc}
\hline & \multicolumn{5}{c}{ Predicted } \\
\cline { 2 - 7 } & $(1)$ & $(2)$ & $(3)$ & $(4)$ & $(5)$ \\
\hline T1: Pure honey (1) & 30 & 0 & 0 & 0 & 0 \\
T2: 5\% adulteration (2) & 0 & 30 & 0 & 0 & 0 \\
Actual & T3: 10\% adulteration (3) & 1 & 0 & 29 & 0 & 0 \\
T4: 20\% adulteration (4) & 0 & 0 & 0 & 30 & 0 \\
T5: 30\% adulteration (5) & 0 & 0 & 0 & 0 & 30 \\
\hline
\end{tabular}

much as 34 wavelengths were found to be the most significant to discriminate the different treatments. This procedure is adopted and adapted from Wang and Sousa, 2009. Significant wavelengths were selected based on the high discriminatory power of features as listed in Table 11 .

\section{Conclusion}

In this study, the transmittance rate of pure stingless bee honey showed the highest mean value compared to other treatment at $787.677 \mathrm{~nm}$. Pure stingless bee honey also showed highest SSC and RI value compared to the adulterated sample. There is a significant difference between pure and adulterated stingless bee honey for both SSC and RI. The results of PCA-LDA, PCA-QDA and PCA-SVM as data reduction and classification methods indicated that all these methods are equally good in classifying the samples into different treatments based on the VIS-NIR properties data with $99.33 \%$ accuracy. The PCA and linear discriminant technique revealed as much as 34 wavelengths that were found to be the most significant to discriminate the different treatments. More detailed work is planned to be carried out to acquire more accurate data that can be used to develop a rapid prediction of adulteration in stingless bee honey in the future.

Table 9. Summary of misclassified observations

\begin{tabular}{cccccc}
\hline Observation & True Group & Predicted Group & Group & Squared Distance Probability \\
\hline $16 * *$ & T3: $10 \%$ adulteration & T1: Pure honey & T1: Pure honey & 15.04 & 1.00 \\
& & T2: $5 \%$ adulteration & 338.56 & 0.00 \\
& & T3: $10 \%$ adulteration & 41.07 & 0.00 \\
& & T4: $20 \%$ adulteration & 4291.5 & 0.00 \\
& & T5: $30 \%$ adulteration & 620.78 & 0.00 \\
\hline
\end{tabular}


Table 11. Significant wavelengths according to the transmittance rate of stingless bee honey

Selected wavelengths $(\mathrm{nm})$

$834.073,850.81,851.301,861.599,863.068,863.313,863.558,863.803,864.047,864.537,865.515,865.76,866.004,866.738$, $867.227,867.471,867.716,867.96,868.449,868.693,869.182,869.671,869.915,870.404,870.892,871.136,871.625,871.869$, $872.113,873.089,873.333,873.578,873.822$ and 885.515.

\section{Acknowledgement}

This study was supported by the Fundamental Research Grant Scheme (Ref no.: FRGS/1/2008/TK04/ UPM/02/13) awarded by the Malaysia Ministry of Education.

\section{References}

Amin, Z., Aina, F., Sabri, S., Mohammad, S.M., Ismail, M., Chan, K.W. and Zawawi, N. (2018). Therapeutic properties of stingless bee honey in comparison with European bee honey. Advances in Pharmacological and Pharmaceutical Sciences, 2018, 6179596. https://doi.org/10.1155/2018/6179596

Ávila, S., Hornung, P.S., Teixeira, G.L., Beux, M.R., Lazzarotto, M. and Ribani, R.H. (2018). A chemometric approach for moisture control in stingless bee honey using near infrared spectroscopy. Journal of Near Infrared Spectroscopy, 26(6), 379-388. https:// doi.org/10.1177/0967033518805254

Balabin, R.M., Safieva, R.Z. and Lomakina, E.I. (2010). Gasoline classification using near infrared (NIR) spectroscopy data: Comparison of multivariate techniques. Analytica Chimica Acta, 671(1-2), 2735. https://doi.org/10.1016/j.aca.2010.05.013

Bázár, G., Romvári, R., Szabó, A., Somogyi, T., Éles, V. and Tsenkova, R. (2016). NIR detection of honey adulteration reveals differences in water spectral pattern. Food Chemistry, 194, 873-880. https:// doi.org/10.1016/j.foodchem.2015.08.092

Biluca, F.C., Braghini, F., Gonzaga, L.V., Costa, A.C.O. and Fett, R. (2016). Physicochemical profiles, minerals and bioactive compounds of stingless bee honey (Meliponinae). Journal of Food Composition and Analysis, 50, 61-69. https://doi.org/10.1016/ j.jfca.2016.05.007

Borràs, E., Ferré, J., Boqué, R., Mestres, M., Aceña, L. and Busto, O. (2015). Data fusion methodologies for food and beverage authentication and quality assessment-A review. Analytica Chimica Acta, 891, 1-14. https://doi.org/10.1016/j.aca.2015.04.042

Cabanero, A.I., Recio, J.L. and Ruperez, M. (2006). Liquid chromatography coupled to isotope ratio mass spectrometry: a new perspective on honey adulteration detection. Journal of Agricultural and Food Chemistry, 54(26), 9719-9727. https:// doi.org/10.1021/jf062067x
Chen, L., Xue, X., Ye, Z., Zhou, J., Chen, F. and Zhao, J. (2011). Determination of Chinese honey adulterated with high fructose corn syrup by near infrared spectroscopy. Food Chemistry, 128(4), 1110-1114. https://doi.org/10.1016/j.foodchem.2010.10.027

Chuttong, B., Chanbang, Y., Sringarm, K. and Burgett, M. (2016). Physicochemical profiles of stingless bee (Apidae: Meliponini) honey from South East Asia (Thailand). Food Chemistry, 192, 149-155. https:// doi.org/10.1016/j.foodchem.2015.06.089

Codex Alimentarius Commission. (2001). CODEX STAN 12-1981. Standard for Honey. Rome: Codex Alimentarius Commission, FAO.

Cordella, C., Faucon, J.P., Cabrol-Bass, D. and Sbirrazzuoli, N. (2003). Application of DSC as a tool for honey floral species characterization and adulteration detection. Journal of Thermal Analysis and Calorimetry, 71(1), 279-290. https:// doi.org/10.1023/A:1022251208688

Cortopassi-Laurino, M., Imperatriz-Fonseca, V.L., Roubik, D.W., Dollin, A., Heard, T., Aguilar, I. and Nogueira-Neto, P. (2006). Global meliponiculture: challenges and opportunities. Apidologie, 37(2), 275292. https://doi.org/10.1051/apido:2006027

Cotte, J.F., Casabianca, H., Giroud, B., Albert, M., Lheritier, J. and Grenier-Loustalot, M.F. (2004). Characterization of honey amino acid profiles using high-pressure liquid chromatography to control authenticity. Analytical and Bioanalytical Chemistry, 378(5), 1342-1350. https:// doi.org/10.1007/s00216-003-2430-z

Department of Standards Malaysia. (2017). MS 2683: 2017 Kelulut (Stingless Bee) HoneySpecification. Malaysia.

Friedman, J., Hastie, T. and Tibshirani, R. (2001). The elements of statistical learning. Vol. 1. New York: Springer Series in Statistics.

Gallardo-Velázquez, T., Osorio-Revilla, G., Zuñiga-de Loa, M. and Rivera-Espinoza, Y. (2009). Application of FTIR-HATR spectroscopy and multivariate analysis to the quantification of adulterants in Mexican honeys. Food Research International, 42(3), 313-318. https:// doi.org/10.1016/j.foodres.2008.11.010

Kek, S.P., Chin, N.L., Yusof, Y.A., Tan, S.W. and Chua, L.S. (2014). Total phenolic contents and colour intensity of Malaysian honeys from the Apis spp. 
and Trigona spp. bees. Agriculture and Agricultural Science Procedia, 2, 150-155. https:// doi.org/10.1016/j.aaspro.2014.11.022

Kelly, J.D., Petisco, C. and Downey, G. (2006). Potential of near infrared transflectance spectroscopy to detect adulteration of Irish honey by beet invert syrup and high fructose corn syrup. Journal of Near Infrared Spectroscopy, 14(2), 139-146. https:// doi.org/10.1255/jnirs.599

Khaled, A.Y., Abd Aziz, S., Bejo, S.K., Nawi, N.M., Jamaludin, D. and Ibrahim, N.U.A. (2020). A comparative study on dimensionality reduction of dielectric spectral data for the classification of basal stem rot (BSR) disease in oil palm. Computers and Electronics in Agriculture, 170, 105288. https:// doi.org/10.1016/j.compag.2020.105288

Kim, H.C., Kim, D. and Bang, S.Y. (2003). Extensions of LDA by PCA mixture model and class-wise features. Pattern Recognition, 36(5), 1095-1105. https://doi.org/10.1016/S0031-3203(02)00163-2

Li, Y. and Yang, H. (2012). Honey discrimination using visible and near-infrared spectroscopy. ISRN Spectroscopy, 2012, 4874040. https:// doi.org/10.5402/2012/487040

Liu, Q., Weng, P. and Wu, Z. (2020). Quality and aroma characteristics of honey peach wines as influenced by different maturity. International Journal of Food Properties, 23(1), 445-458. https:// doi.org/10.1080/10942912.2020.1736094

Masnan, M.J., Mahat, N.I., Zakaria, A., Shakaff, A.Y.M., Adom, A.H. and Sa'ad, F.S.A. (2012). Enhancing classification performance of multisensory data through extraction and selection of features. Procedia Chemistry, 6, 132-140. https:// doi.org/10.1016/j.proche.2012.10.139

Mavroforakis, M.E. and Theodoridis, S. (2006). A geometric approach to support vector machine (SVM) classification. IEEE Transactions on Neural Networks, 17(3), 671-682. https://doi.org/10.1109/ TNN.2006.873281

Mehryar, L. and Esmaiili, M. (2011). Honey and honey adulteration detection: A review presented at the 11th International Congress on Engineering and Food, Vol. 3, p. 1713 - 1714. Athens, Greece.

Naila, A., Flint, S.H., Sulaiman, A.Z., Ajit, A. and Weeds, Z. (2018). Classical and novel approaches to the analysis of honey and detection of adulterants. Food Control, 90, 152-165. https:// doi.org/10.1016/j.foodcont.2018.02.027

Noble, W.S. (2006). What is a support vector machine? Nature Biotechnology, 24(12), 1565-1567. https:// doi.org/10.1038/nbt1206-1565
Padovan, G.J., De Jong, D., Rodrigues, L.P. and Marchini, J.S. (2003). Detection of adulteration of commercial honey samples by the $13 \mathrm{C} / 12 \mathrm{C}$ isotopic ratio. Food Chemistry, 82(4), 633-636. https:// doi.org/10.1016/S0308-8146(02)00504-6

Paradkar, M.M. and Irudayaraj, J. (2002). Discrimination and classification of beet and cane inverts in honey by FT-Raman spectroscopy. Food Chemistry, 76(2), 231-239. https://doi.org/10.1016/S0308-8146(01) 00292-8

Ruiz-Matute, A.I., Brokl, M., Soria, A.C., Sanz, M.L. and Martínez-Castro, I. (2010). Gas chromatographic -mass spectrometric characterisation of tri-and tetrasaccharides in honey. Food Chemistry, 120(2), 637-642.

https://doi.org/10.1016/

j.foodchem.2009.10.050

Skrobot, V.L., Castro, E.V., Pereira, R.C., Pasa, V.M. and Fortes, I.C. (2007). Use of principal component analysis (PCA) and linear discriminant analysis (LDA) in gas chromatographic (GC) data in the investigation of gasoline adulteration. Energy and Fuels, 21(6), 3394-3400. https://doi.org/10.1021/ ef0701337

Souza, B.A., Roubik, D.W., Barth, O.M., Heard, T.A., Enríquez, E., Carvalho, C., Villas-Boas, J., Marchini, L., Locatelli, J., Persano-Oddo, L., AlmeidaMuradian, L., Bognadov, S. and Vit, P. (2006). Composition of stingless bee honey: setting quality standards. Interciencia, 31, 867-875.

Terrab, A., Recamales, A.F., Hernanz, D. and Heredia, F.J. (2004). Characterisation of Spanish thyme honeys by their physicochemical characteristics and mineral contents. Food Chemistry, 88(4), 537-542. https://doi.org/10.1016/j.foodchem.2004.01.068

Vapnik, V.N. and Chervonenkis, A.Y. (1982). Necessary and sufficient conditions for the uniform convergence of means to their expectations. Theory of Probability and Its Applications, 26(3), 532-553. https://doi.org/10.1137/1126059

Vijayakumar, K. and Jeyaraaj, R. (2014). Taxonomic notes on Trigona (Tetragonula) iridipennis Smith (Hymenoptera: Apidae) from India. Journal of Threatened Taxa, 6(11), 6480-6484. https:// doi.org/10.11609/JoTT.03773.6480-4

Wang, L.E. and Sousa, W.P. (2009). Distinguishing mangrove species with laboratory measurements of hyperspectral leaf reflectance. International Journal of Remote Sensing, 30(5), 1267-1281. https:// doi.org/10.1080/01431160802474014

Welch, B.L. (1939). Note on discriminant functions. Biometrika, 31(1/2), 218-220. https:// doi.org/10.2307/2334985 
White Jr, J.W. (1979). Spectrophotometric method for hydroxymethylfurfural in honey. Journal of the Association of Official Analytical Chemists, 62(3), 509-514. https://doi.org/10.1093/jaoac/62.3.509

Won, S.R., Lee, D.C., Ko, S.H., Kim, J.W. and Rhee, H.I. (2008). Honey major protein characterization and its application to adulteration detection. Food Research International, 41(10), 952-956. https:// doi.org/10.1016/j.foodres.2008.07.014

Ya'akob, H., Norhisham, N.F., Mohamed, M., Sadek, N. and Endrini, S. (2019). Evaluation of Physicochemical Properties of Trigona sp. Stingless Bee Honey from Various Districts of Johor. Jurnal Kejuruteraan SI, 2(1), 59-67.

Yanniotis, S., Skaltsi, S. and Karaburnioti, S. (2006). Effect of moisture content on the viscosity of honey at different temperatures. Journal of Food Engineering, 72(4), 372-377. https:// doi.org/10.1016/j.jfoodeng.2004.12.017

Zábrodská, B. and Vorlová, L. (2015). Adulteration of honey and available methods for detection-a review. Acta Veterinaria Brno, 83(10), 85-102. https://doi.org/10.2754/avb201483S10S85

Zhu, X., Li, S., Shan, Y., Zhang, Z., Li, G., Su, D. and Liu, F. (2010). Detection of adulterants such as sweeteners materials in honey using near-infrared spectroscopy and chemometrics. Journal of Food Engineering, 101(1), 92-97. https://doi.org/10.1016/ j.jfoodeng.2010.06.014 